\title{
A Study on the Serum y-Glutamyltranspeptidase and Plasma Osteopontin in Alcoholic Liver Disease
}

\author{
Arpita Suri ${ }^{1}$ Naveen Singh ${ }^{1}$ Sanjiv Kumar Bansal ${ }^{1}$ \\ ${ }^{1}$ Department of Biochemistry, Faculty of Medicine and Health \\ Sciences, SGT University, Gurugram, Haryana, India \\ J Lab Physicians 2022;14:101-108.

\begin{abstract}
Address for correspondence Naveen Singh, MSc, Department of Biochemistry, Faculty of Medicine and Health Sciences, SGT University, Gurugram, Haryana, 122505, India
\end{abstract} \\ (e-mail: singh.naveen95@gmail.com).
}

\begin{abstract}
Keywords

- GGT

- osteopontin

- alcoholic liver disease

- AST

- ALT

- ALP

Background Alcoholic liver disease (ALD) is a major source of alcohol-related morbidity and mortality. Heavy drinkers and alcoholics may progress from fatty liver to alcoholic hepatitis to cirrhosis. The enzyme $\gamma$-glutamyltranspeptidase (GGT) is a membrane-bound glycoprotein which catalyzes the transfer of the $\gamma$-glutamyl group from $y$-glutamyl peptides to other peptides, amino acids, and water. Serum GGT activity mainly attributed to hepatobiliary system and thus is an important marker of ALD. Hence the present study is conducted to estimate and correlate the levels of GGT and osteopontin (OPN) in ALD.

Aims and Objectives The objective of this study is to estimate and correlate the levels of GGT and OPN in ALD.

Materials and Methods Sixty clinically diagnosed cases of ALD and sixty age- and gender-matched healthy controls were recruited for the study. Blood samples were collected from them and serum aspartate aminotransferase, serum alanine transaminases (ALTs), serum ALP levels, and plasma OPN levels were measured. Estimation of serum aspartate transaminases (AST), ALTs, and alkaline phosphatase (ALP) was assayed by standard photometric methods in autoanalyzer ERBA-XL (EM-200) using commercially available kits. OPN was estimated by using commercial kit based on enzyme-linked immunosorbent assay.

Results The parameters of the liver function tests such as AST, ALT, and ALP were significantly increased in patients with $\operatorname{ALD}(p<0.001)$ when compared with the healthy control subjects. In the present study, significantly increased levels of $y$-glutamyl transferases and OPN were found in patients with $\operatorname{ALD}(p<0.001)$ when compared with the control subjects. OPN showed significant positive correlations with AST $(r=0.76, p<0.001)$, ALT $(r=0.64, p<0.001)$, ALP $(r=0.68, p<0.001)$, and GGT $(r=0.61, p<0.001)$.

Conclusion The present study focuses on the role of GGT and OPN that are sensitive indicators of liver cell injury and are most helpful in recognizing hepatocellular diseases such as ALD, hepatitis, and liver cirrhosis. Hence, the pattern of the GGT and OPN levels elevation can be helpful diagnostically.
\end{abstract}

published online July 9, 2021
DOI https://doi.org/

10.1055/s-0041-1729479. ISSN 0974-2727. (c) 2021. The Indian Association of Laboratory Physicians. All rights reserved.

This is an open access article published by Thieme under the terms of the Creative Commons Attribution-NonDerivative-NonCommercial-License, permitting copying and reproduction so long as the original work is given appropriate credit. Contents may not be used for commercial purposes, or adapted, remixed, transformed or built upon. (https://creativecommons.org/ licenses/by-nc-nd/4.0/)

Thieme Medical and Scientific Publishers Pvt. Ltd., A-12, 2nd Floor, Sector 2, Noida-201301 UP, India 


\section{Introduction}

Alcohol remains a major cause of liver disease worldwide. The amount of alcohol ingested (independent of the form in which it is ingested) is the most important risk factor for the development of alcoholic liver disease (ALD). ${ }^{1}$ Alcoholism remains the most important and apparent cause of cirrhosis, especially in the Western world. Intake of $80 \mathrm{~g}$ of alcohol per day has been defined as "hazardous drinking" and consumption of amounts in excess significantly increases the risk of developing cirrhosis. ${ }^{2}$ ALD is a major source of alcoholrelated morbidity and mortality. Heavy drinkers and alcoholics may progress from fatty liver to alcoholic hepatitis (AH) to cirrhosis, and it is estimated that 10 to $15 \%$ of alcoholics will develop cirrhosis. ${ }^{3}$ The risk of developing cirrhosis increases with an average alcohol ingestion of $>60$ to $80 \mathrm{~g} / \mathrm{d}$ in men and $>20 \mathrm{~g} / \mathrm{d}$ for $\geq 10$ years in women (A unit of alcohol contains $8 \mathrm{~g}$ of ethanol). ${ }^{4,5} \mathrm{~A}$ threshold for developing ALD is variable but begins at $30 \mathrm{~g} / \mathrm{d}$ of ethanol. However, there is no clear linear relationship between dose and liver damage. ${ }^{6}$ Previous studies have reported that in $90 \%$ of individuals who had continued alcohol use ( $>40 \mathrm{~g} / \mathrm{d}$ ), there was an increased risk of progression to cirrhosis in $30 \%$, and fibrosis or cirrhosis in $37 \% .^{7,8}$ The aim of the present study is to determine the correlation of GGT with osteopontin (OPN) and liver enzymes in the diagnosis of ALD. The enzyme $\gamma$-glutamyltranspeptidase (GGT) is a membrane bound glycoprotein which catalyzes the transfer of the $\gamma$ glutamyl group from $\gamma$-glutamyl peptides to other peptides, amino acids, and water. ${ }^{9}$ It occurs predominantly as a membrane bound enzyme in significant amounts only in the kidney, pancreas, liver, spleen, and small intestine. GGT is a microsomal enzyme present in hepatocytes and biliary epithelial cells, renal tubules, pancreas, and intestine. ${ }^{10}$ It is also present in cell membrane performing transport of peptides into the cell across the cell membrane and involved in glutathione metabolism. Serum GGT activity mainly attributed to hepatobiliary system even though it is found in more concentration in renal tissue. ${ }^{11}$ Raised serum activity of the enzyme has been reported in alcoholism, various forms of liver diseases including primary and secondary hepatic tumors, diabetes mellitus, cardiovascular disease, renal neoplasms, and the nephrotic syndrome. A recent study of its value in liver disease has shown that serum GGT activity correlates closely with the activity of alkaline phosphatase (ALP) and 5-nucleotidase, and that compared with these two other enzymes, GGT is a more sensitive index of biliary tract disease. ${ }^{10}$ OPN first described as a phosphoprotein was secreted by a transformed cell line in 1979. Several years later, the bone-specific sialoprotein was cloned as a matrix protein and termed as OPN. ${ }^{12}$ OPN is located on chromosome 4 region 22 (4q22.1) in humans and is composed of approximately 300 amino acids ( 314 in human, but 297 in mouse). The multifunctionality of OPN is due to varied post-translational modifications such as phosphorylation, sulfation, glycosylation, and proteolytic cleavage. OPN contains an arginine-glycine-aspartate domain, which binds with high affinity to integrins such as $\alpha v \beta 1, \alpha v \beta 3, \alpha v \beta 5$, $\alpha v \beta 6, \alpha 8 \beta 1$, and $\alpha 5 \beta 1 .{ }^{13}$ OPN has two isoforms, a secreted form of OPN (sOPN) and an intracellular form of OPN (iOPN). sOPN staining had perinuclear distribution which appeared in Golgi, and iOPN staining had perimembrane distribution. ${ }^{14-16}$ Hepatic expression and plasma levels of OPN are markedly elevated in patients with $\mathrm{AH}$, alcoholic cirrhosis, and end stage ALD. ${ }^{17}$ OPN is progressively increased in liver fibrosis and is associated with the stage of fibrosis. ${ }^{9}$ OPN may play a protective role and its deficiency facilitates the development of $\mathrm{AH}$, neutrophilic inflammation, and high mortality rate. It is established that OPN could bind to gut-derived lipopolysaccharides and prevent macrophage activation, reactive oxygen species, nitrogen species generation, and tumor necrosis factor- $\alpha$ (TNF $\alpha){ }^{18}$

\section{Materials and Methods}

The present hospital-based cross-sectional case-control study was performed in the Department of Biochemistry and Medicine, Faculty of Medicine \& Health Sciences, SGT Medical College, Hospital \& Research Institute (SGT University), Gurugram, Haryana. Sixty clinically diagnosed patients of ALD in the age group of 20 to 60 years attending Medicine OPD of SGT Hospital, Budhera, Gurugram were included as the cases. Cases were defined based on medical history, physical examination, and laboratory investigations. Sixty (60) age- and gender-matched healthy volunteers from general population were taken as controls.

After explaining, the purpose and details of the study to all the subjects of both the groups, a written and informed consent was taken. Ethical clearance was obtained from the Institutional Ethical Committee before starting the collection of samples. Patients with alcohol intake $\geq 100 \mathrm{~g} / \mathrm{d}$, duration of alcohol intake $>8$ years and serum aspartate transaminases (AST) levels two to six times raised as compared with alanine transaminases (ALT) were included as cases. Patients with viral hepatitis B and C, autoimmune hepatitis, druginduced hepatitis, copper and iron storage disease (Wilson disease, hemochromatosis), chronic smoking, steroids, antihypertensive drugs, hypoglycemic drugs or hormone replacement therapy, concomitant inflammatory disorders, and renal disorders (was ruled out on the basis of kidney function test) were excluded from the study.

A total of $5 \mathrm{~mL}$ of venous blood was collected after 12 to 14 hours of fasting taking all aseptic precautions. Out of $5 \mathrm{~mL}$, $3 \mathrm{~mL}$ was collected in plain vial and serum was separated by centrifuging at 3,000 rpm for 10 to 15 minutes and $2 \mathrm{~mL}$ blood was collected in an ethylenediaminetetraacetic acid (EDTA) containing vial for the estimation of OPN. Liver function tests of the subjects were estimated immediately, and one aliquot was preserved at $20^{\circ} \mathrm{C}$ for the estimation of OPN within 1 month of collection of samples. Internal quality control for all the tests was performed using control materials obtained from ERBA, Germany.

Estimation of AST, ALT, ALP, and $\gamma$-glutamyl transferases (GGT) was assayed by standard photometric methods in autoanalyzer ERBA-XL (EM-200) using commercially available kits. 
GGT was estimated by The International Federation of Clinical Chemistry and Laboratory Medicine (IFCC) method with L- $\gamma$-glutamyl-3-carboxy-4-nitroanilide as substrate. GGT present in the sample catalyzes the transfer of the glutamyl group from the substrate $\gamma$-glutamyl-3-carboxy4-nitroanilide to glycylglycine forming glutamyl-glycyl-glycine and 5-amino-2-nitrobenzoate.The rate of formation of 5-amino-2-nitrobenzoate is proportional to the activity of GGT present in the sample and can be measured kinetically at 400 to $420 \mathrm{~nm}$. Reference range for males: $<55 \mathrm{U} / \mathrm{L}$ and for females: $<38 \mathrm{U} / \mathrm{L}$.

Human OPN immunoassay (Quantikine ELISA, United States of America. Catalog No. DOST00) employs the quantitative sandwich enzyme immunoassay technique. A monoclonal antibody specific for human OPN has been precoated onto a microplate. Standards and samples are pipetted into the wells and any OPN present was bound by the immobilized antibody. After washing away any unbound substances, an enzyme-linked polyclonal antibody specific for human OPN was added to the wells. Following a wash to remove any unbound antibody-enzyme reagent, a substrate solution was added to the wells and color develops in proportion to the amount of OPN bound in the initial step. The color development was stopped and the intensity of the color was measured. Reference range is $53.4 \mathrm{ng} / \mathrm{mL}$ to $195 \mathrm{ng} / \mathrm{mL}$.

Serum aspartate aminotransferase (AST) was estimated by IFCC recommended method without pyridoxal phosphate. AST present in the sample catalyzes the transfer of the amino group from L-aspirate to 2-oxoglutarate forming oxaloacetate and L-glutamate. Oxaloacetate in the presence of NADH and malate dehydrogenase is reduced to L-malate. In this reaction, $\mathrm{NADH}$ is oxidized $\mathrm{NADH}^{+}$. The reaction is monitored by measuring the rate of decrease in absorbance at $340 \mathrm{~nm}$ due to oxidation of $\mathrm{NADH}$ to $\mathrm{NAD}^{+}$. Addition of lactate dehydrogenase ( $\mathrm{LDH}$ ) to the reagent is necessary to achieve rapid and complete reduction of endogenous pyruvate so that it is does not interfere with the assay. Reference range for male is up to $35 \mathrm{U} / \mathrm{L}$ and for female is up to $31 \mathrm{U} / \mathrm{L}$.

Serum ALT was estimated by IFCC recommended method without pyridoxal phosphate. The amino group is enzymatically transferred by ALT present in the sample from alanine to the carbon atom of 2-oxoglutrate yielding pyruvate and Lglutamate. Pyruvate is reduced to lactate by LDH present in the reagent with the simultaneous oxidation of NADH to $\mathrm{NAD}^{+}$. The reaction was monitored by measuring the rate of decrease in absorbance at $340 \mathrm{~nm}$ due to the oxidation of NADH. Endogenous sample pyruvate was rapidly and completely reduced by LDH during initial incubation period to avoid interference during assay. Reference range in males is up to $45 \mathrm{U} / \mathrm{L}$ and in females is up to $34 \mathrm{U} / \mathrm{L}$.

ALP was estimated by 2-amino-2-methyl-1-propanol method. This method utilizes 4-nitrophenyl phosphate as the substrate. At the $\mathrm{pH}$ of the reaction, 4-nitrophenol has an intense yellow color. The reagent also contains a metal ion buffer system to ensure that optimal concentrations of zinc and magnesium are maintained. The metal ion buffer can also chelate other potentially inhibitory ions which may be present. The reaction is monitored by measuring the rate of increase in absorbance at $415 \mathrm{~nm}$ which is proportional to the activity of ALP in the serum. Reference range in male is 53 to $128 \mathrm{U} / \mathrm{L}$ for 20 to 59 years and 56 to $119 \mathrm{U} / \mathrm{L}$ for $\geq 60$ years. For females between 20 and 59 years it is 42 to $98 \mathrm{U} / \mathrm{L}$ and for females $\geq 60$ years it is 53 to $141 \mathrm{U} / \mathrm{L}$.

\section{Statistical Analysis}

The data recorded was entered in a spreadsheet and then statistical analyses were performed by using Statistical Package for the Social Sciences (SPSS) Version 21.0. Continuous variables were summarized in the form of means and standard deviations. Graphical data was presented by bar diagrams. Student's independent $t$-test was employed for comparing continuous variables. Pearson's correlations coefficient was applied to study the association of OPN with liver enzymes of ALD patients. The $p$-value $(p<0.05)$ was considered statistically significant for all the parameters.

\section{Results}

The mean age of the ALD patients was $53.06 \pm 4.38$ years and for the healthy controls was $50.76 \pm 5.89$ years ( - Table 1 ). In our study, $93 \%$ cases of ALD were males $(n=56)$ and $7 \%$ were females $(n=4)$, whereas $92 \%$ of the controls were males $(n=$ $55)$ and $7 \%$ were females $(n=5)$ (-Figs. 1 and $\mathbf{2}$ ).

The parameters of the liver function tests such as AST, ALT, and ALP were significantly increased in the patients with ALD $(p<0.001)$ when compared with the healthy control subjects (-Table 2).

- Table 3 showed significant increase in the parameters of liver function tests (AST, ALT, ALP, and AST/ALT ratio) of ALD patients when compared with the controls and was statistically significant at the level of $p<0.001$ (-Figs. 3-5).

In the present study, significantly increased levels of GGT and OPN were found in the patients with ALD $(p<0.001)$ when compared with the control subjects ( $\mathbf{- T a b l e ~} \mathbf{2}$ ).

-Table 2 showed significant increase in the levels of markers of ALD (GGT and OPN) of ALD patients when

Table 1 Demographic parameters of the subjects

\begin{tabular}{|l|l|l|l|}
\hline Parameters & & Cases $(\boldsymbol{n}=60)$ & Controls $(\boldsymbol{n}=60)$ \\
\hline \multirow{2}{*}{ Sex } & Male & 56 & 55 \\
\cline { 2 - 4 } & Female & 04 & 05 \\
\hline Age (years) & & $53.06 \pm 4.38$ & $50.76 \pm 5.89$ \\
\hline
\end{tabular}


104 The Role of GGT and OPN in Alcoholic Liver Disease Suri et al.

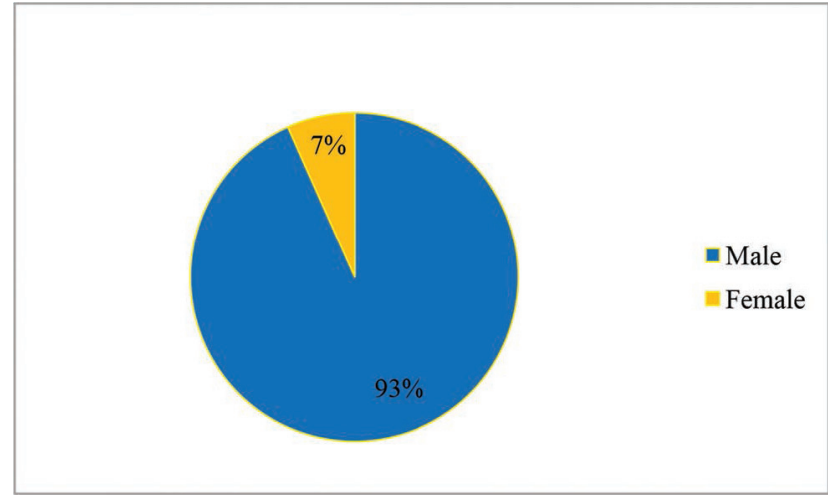

Fig. 1 Distribution of ALD cases according to gender. ALD, alcoholic liver disease.

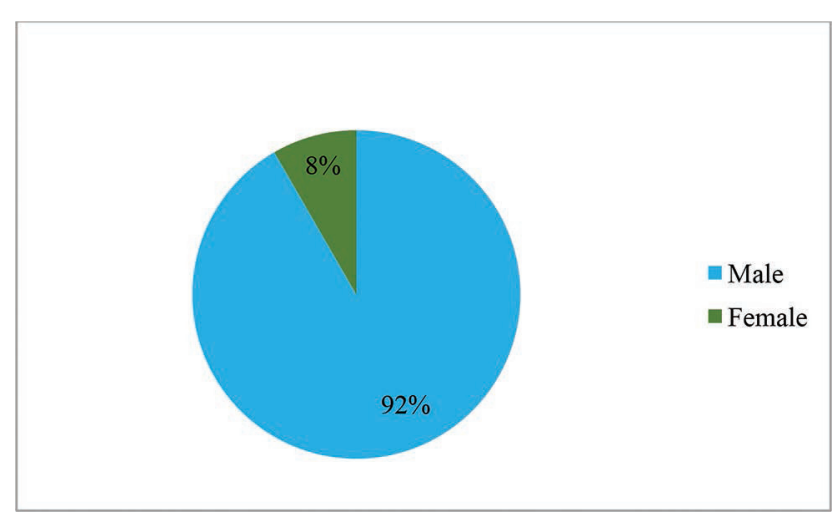

Fig. 2 Distribution of controls according to gender.

Table 2 Comparison of GGT and OPN among ALD patients and control subjects

\begin{tabular}{|l|l|l|l|l|}
\hline Parameters & $\begin{array}{l}\text { Cases } \\
\text { (Mean } \pm \text { SD) }\end{array}$ & $\begin{array}{l}\text { Controls } \\
\text { (Mean } \pm \text { SD) }\end{array}$ & $t$-Value & $0.001^{\text {a }}$ \\
\hline GGT $(\mathrm{U} / \mathrm{L})$ & $46.14 \pm 9.06$ & $28.96 \pm 9.28$ & 10.25 & $0.001^{\mathrm{a}}$ \\
\hline OPN $(\mathrm{ng} / \mathrm{mL})$ & $97.43 \pm 31.59$ & $34.33 \pm 11.28$ & 14.56 & \\
\hline
\end{tabular}

Abbreviations: ALD, alcoholic liver disease; GGT, y-glutamyltranspeptidase; OPN, osteopontin; SD, standard deviation. ${ }^{\mathrm{a}} \mathrm{p}<0.001$

Table 3 Comparison of liver function tests among ALD patients and the controls

\begin{tabular}{|l|l|l|l|l|}
\hline Parameters & $\begin{array}{l}\text { Cases } \\
\text { (Mean } \pm \text { SD) }\end{array}$ & $\begin{array}{l}\text { Controls } \\
\text { (Mean } \pm \text { SD) }\end{array}$ & $t$-Value & $p$-Value \\
\hline AST $(\mathrm{U} / \mathrm{L})$ & $67.48 \pm 9.43$ & $18.86 \pm 3.79$ & 37.04 & $0.001^{\mathrm{a}}$ \\
\hline ALT $(\mathrm{U} / \mathrm{L})$ & $36.58 \pm 5.81$ & $20.98 \pm 5.02$ & 15.72 & $0.001^{\mathrm{a}}$ \\
\hline ALP $(\mathrm{U} / \mathrm{L})$ & $97.90 \pm 29.45$ & $40.26 \pm 8.01$ & 14.62 & $0.001^{\mathrm{a}}$ \\
\hline AST/ALT ratio & $1.86 \pm 0.27$ & $0.93 \pm 0.24$ & 19.73 & $0.001^{\mathrm{a}}$ \\
\hline
\end{tabular}

Abbreviations: ALD, alcoholic liver disease; ALP, alkaline phosphatase; ALT, alanine transaminases; AST, aspartate aminotransferase; SD, standard deviation. ${ }^{a} p<0.001$

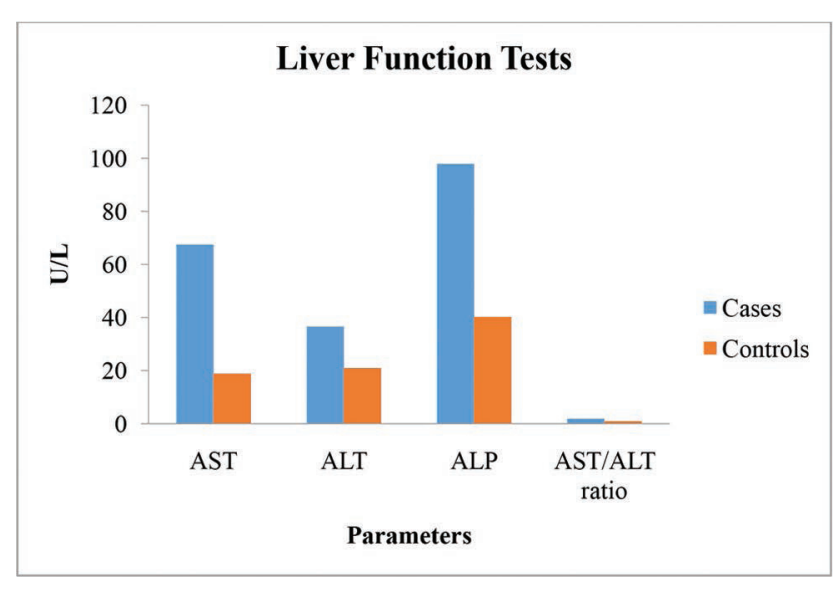

Fig. 3 Graph showing liver function tests of the ALD patients and the controls. ALD, alcoholic liver disease.

compared with the controls and was statistically significant at the level of $p<0.001$.

In the present study significant correlations between the level of OPN and the liver enzymes (AST, ALT and ALP) were found (-Table 4). OPN showed significant positive correlations with
Table 4 Pearson's correlation coefficients of osteopontin (OPN) with liver enzymes

\begin{tabular}{|l|l|l|}
\hline Variables & $\begin{array}{l}\text { Osteopontin } \\
R\end{array}$ & $p$-Value \\
\hline AST & 0.76 & $0.001^{\mathrm{a}}$ \\
\hline ALT & 0.64 & $0.001^{\mathrm{a}}$ \\
\hline ALP & 0.68 & $0.001^{\mathrm{b}}$ \\
\hline GGT & 0.61 & $0.001^{\mathrm{b}}$ \\
\hline
\end{tabular}

Abbreviations: ALP, alkaline phosphatase; ALT, alanine transaminases; AST, aspartate aminotransferase; GGT, $y$-glutamyltranspeptidase.

${ }^{\text {a }}$ Correlation is significant at $\mathrm{p}<0.05$.

${ }^{\mathrm{b}} \mathrm{p}<0.001$

$\operatorname{AST}(r=0.76, p<0.001), \operatorname{ALT}(r=0.64, p<0.001), \operatorname{ALP}(r=0.68$, $p<0.001)$, and GGT $(r=0.61, p<0.001)$ (-Figs. 6-9).

\section{Discussion}

In our study, we found that liver enzymes such as AST, ALT, ALP, and GGT were significantly increased in the patients 


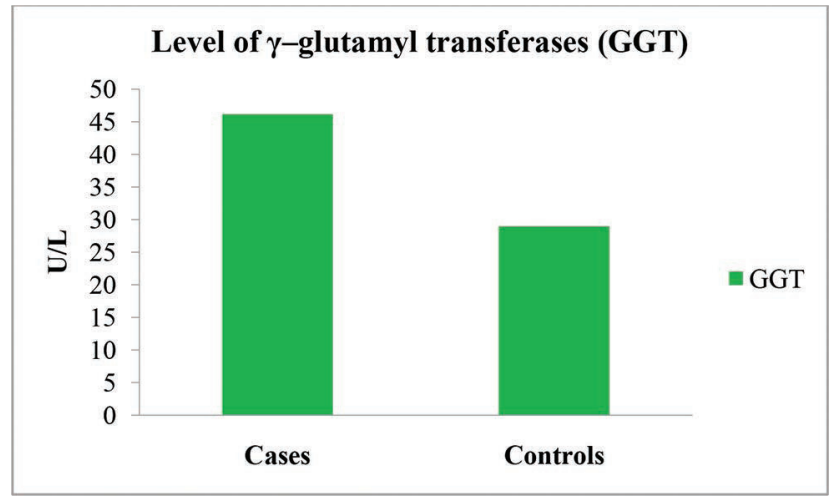

Fig. 4 Graph showing the level of $\gamma$-glutamyl transferases (GGT) of the ALD patients and the controls. ALD, alcoholic liver disease.

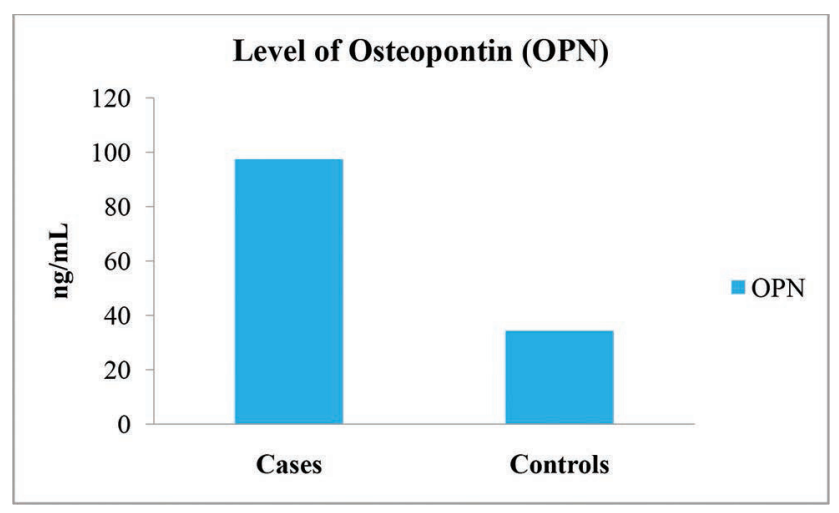

Fig. 5 Graph showing the level of osteopontin (OPN) of the ALD patients and the controls. ALD, alcoholic liver disease.

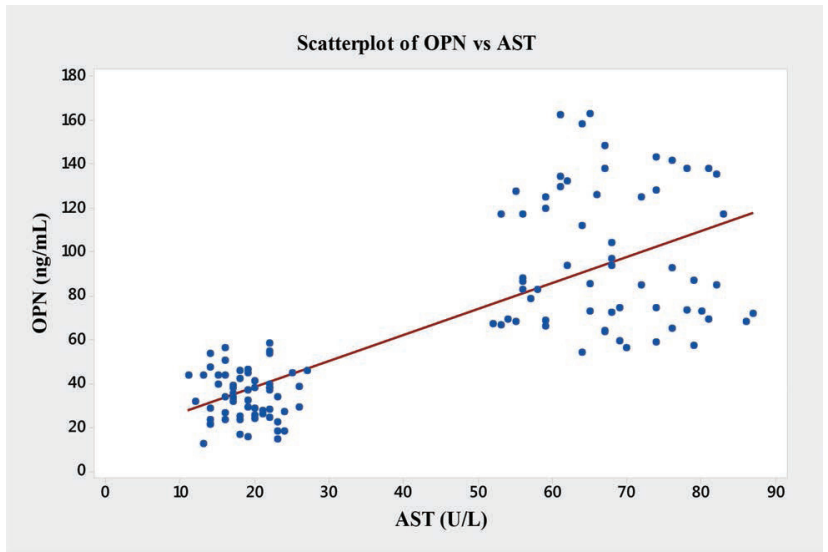

Fig. 6 Graph showing Pearson's correlations of OPN and AST of the subjects. AST, aspartate aminotransferase; OPN, osteopontin.

with ALD $(p<0.001)$ when compared with the healthy control subjects. Similar findings were observed by Cuschieri and Baker, ${ }^{10}$ Konttinen et al, ${ }^{19}$ Matloff et al, ${ }^{20}$ Moussavian et al, ${ }^{21}$ Das and Vasudevan, ${ }^{22}$ Maithreyi et al, ${ }^{23}$ Mirunalini et al, ${ }^{24}$ Jang et al, ${ }^{25} \mathrm{Al}$-Jumaily, ${ }^{26}$ Hyder et al, ${ }^{27}$ Gayathri and Vasantha, ${ }^{28}$ and Brandl et al. ${ }^{29}$ However, our findings are contradictory to the study conducted by Hourigan and Bowling ${ }^{30}$ who found normal levels of serum AST and ALT in patients with alcoholic cirrhosis. Whereas, in the study conducted by Seth et $\mathrm{al}^{31}$ there was no significant difference in serum ALT level between the cases and controls $(p=0.21)$.

In addition, in the study conducted by Teschke et $\mathrm{al}^{32}$ and Benerji et $\mathrm{al}^{33}$, serum ALP in patients with ALD was nonsignificant $(p<0.10)$ when compared with the controls. Similarly, Agarwal et $\mathrm{al}^{34}$ found a significantly lower level of ALP

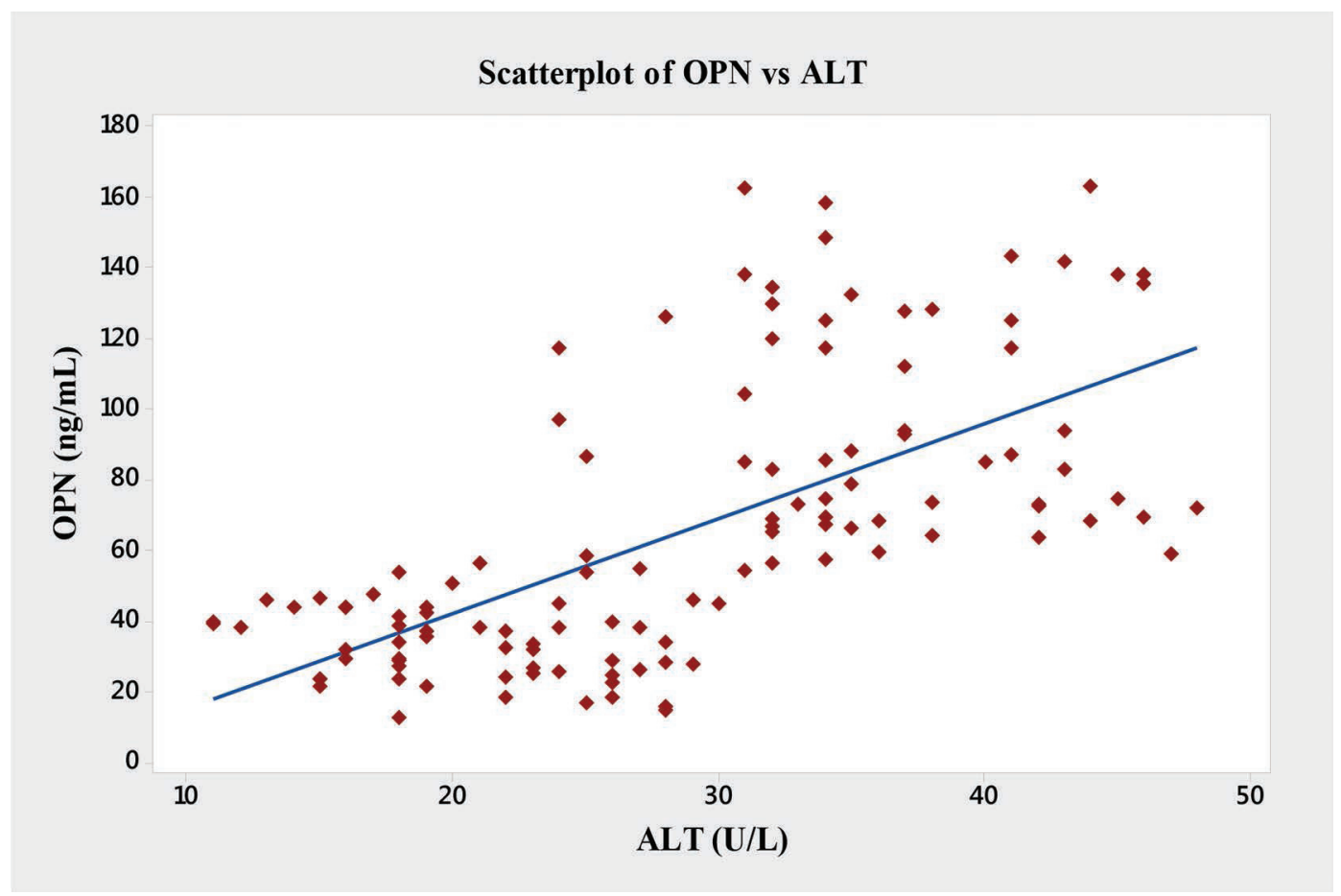

Fig. 7 Graph showing Pearson's correlations of OPN and ALT of the subjects. ALT, alanine transaminases; OPN, osteopontin. 


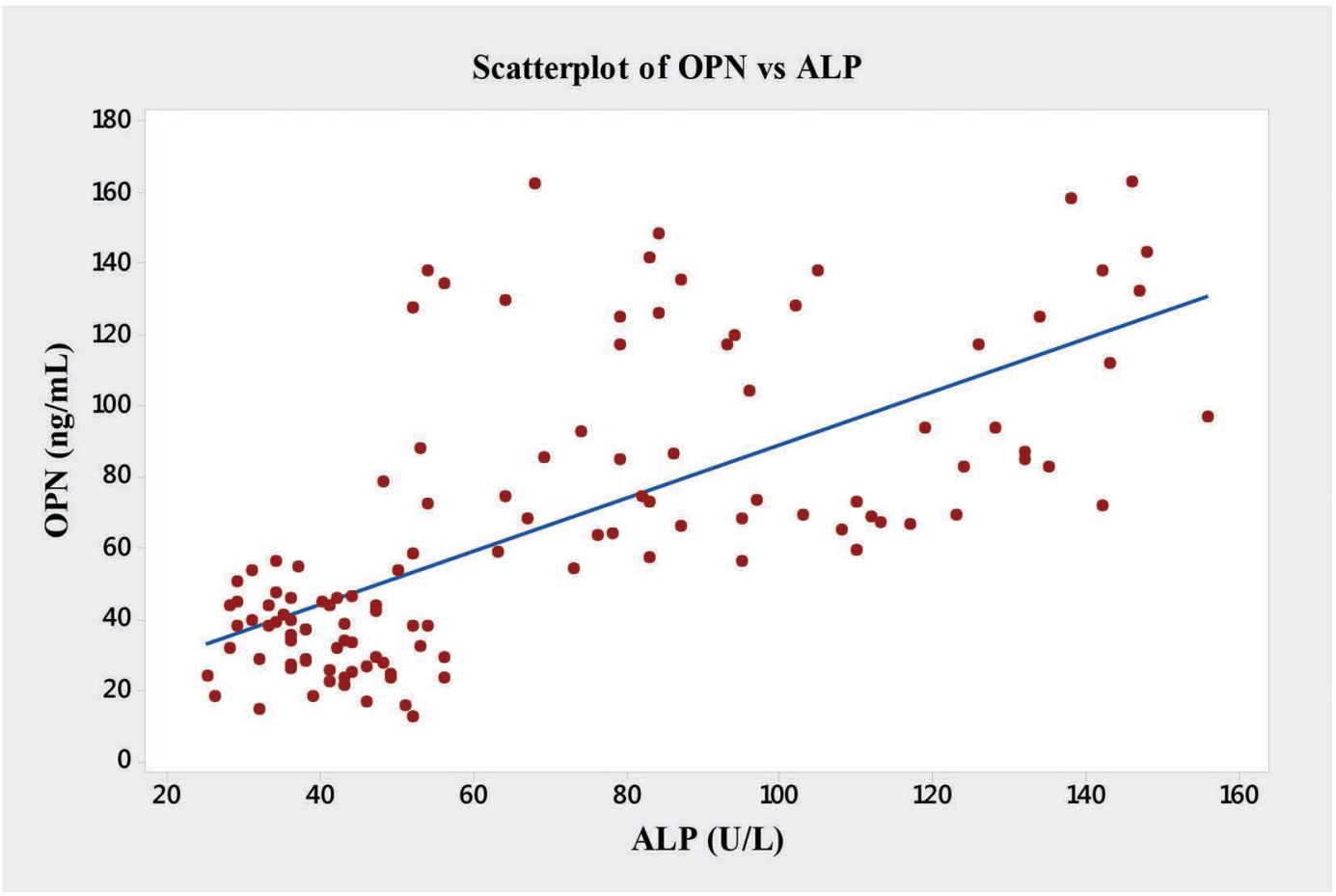

Fig. 8 Graph showing Pearson's correlations of OPN and ALP of the subjects. ALP, alkaline phosphatase; OPN, osteopontin.

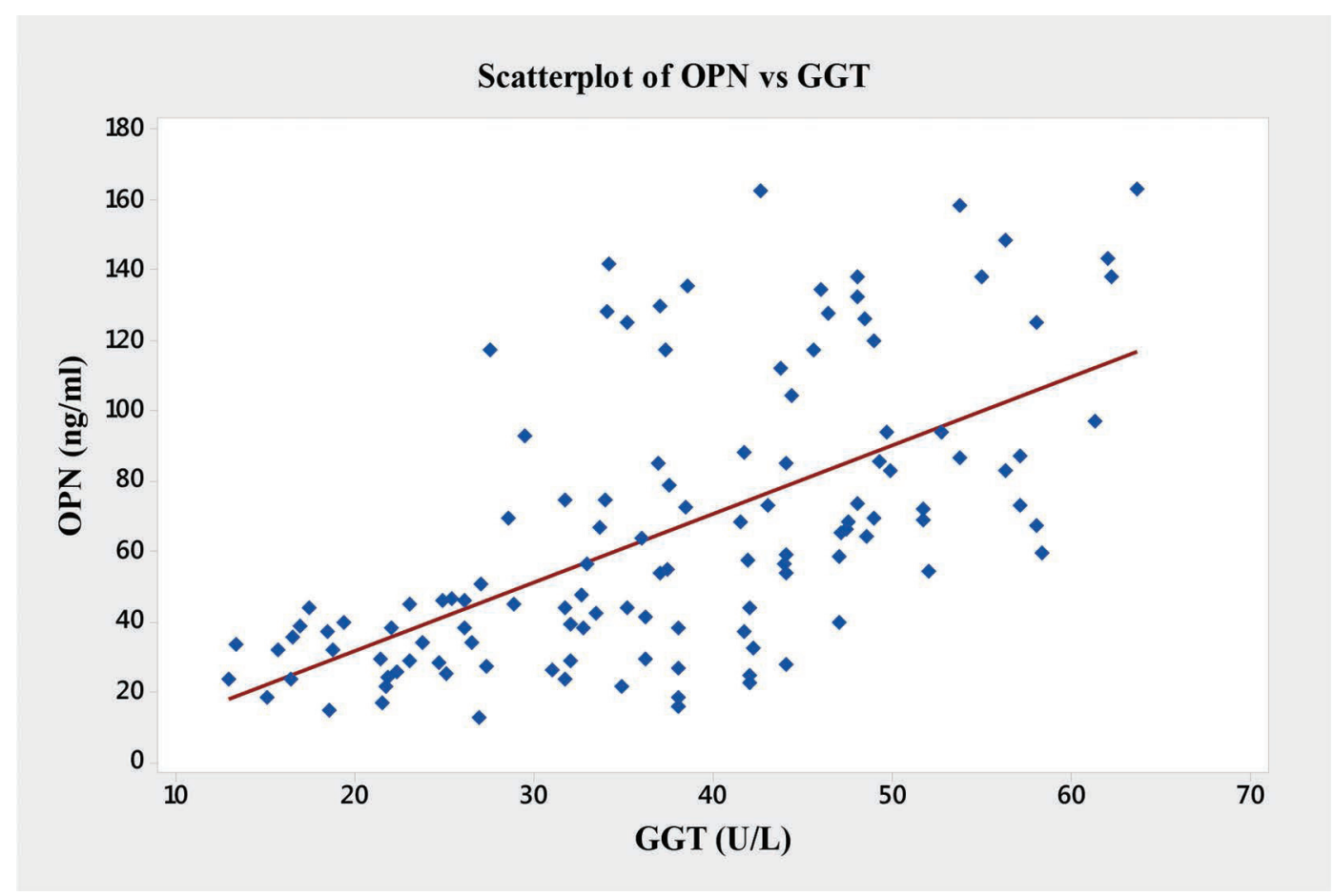

Fig. 9 Graph showing Pearson's correlations of OPN and GGT of the subjects. GGT, y-glutamyltranspeptidase; OPN, osteopontin.

(5-6\%, $p<0.01$ ) in alcohol consumers compared with the nonconsumers.

In our study, we found significant increase in the level of OPN in the patients with ALD $(p<0.001)$ when compared with the control subjects. This is inconsistent with the findings of Wen et $a l,{ }^{13}$ Arai et $a l,{ }^{34}$ Zhao et al, ${ }^{35}$ Patouraux et $\mathrm{al}^{36}$ Seth et ${ }^{31}{ }^{31}$ and Fouad et al. ${ }^{37}$
In the present study, we have also observed novel and significant associations between the level of OPN and the liver enzymes (AST, ALT, ALP, and GGT). OPN showed significant positive correlations with AST $(r=0.76, p<0.001)$, ALT $(r=0.64, p<0.001)$, ALP $(r=0.68, p<0.001)$, and GGT $(r=$ $0.61, p<0.001$ ) (-Fig. 9). We report here for the first time the significant correlation of plasma OPN level with liver 
enzymes in the patients with ALD. However, Moussavian et al reported that, serum levels of GGT correlated significantly with the levels of serum glutamic oxaloacetic transaminase or SGOT ( $p<0.001, r=0.55$ ), serum glutamic pyruvic transaminase or SGPT ( $p<0.001, r=0.45)$, ALP $(p<0.05$, $r=0.49)$, and serum total bilirubin $(p<0.05, r=0.53)$. Further, they concluded that, serum GGT was persistently elevated in alcoholic patients with liver injury. ${ }^{21}$ Gogoi et al found significant correlation in the level of serum GGT in alcoholics when compared with the normal subjects. ${ }^{38}$ Srungaram et al concluded that, OPN levels correlated with the degree of liver necrosis in acute liver failure and very high levels of OPN were associated with hyperactive acute injury and good outcomes. ${ }^{39}$

\section{Conclusion}

The present study focuses on the role of OPN and aminotransferases (transaminases) that are sensitive indicators of liver cell injury and are most helpful in recognizing hepatocellular diseases such as ALD, hepatitis, and liver cirrhosis. Hence, the pattern of the GGT and OPN levels elevation can be helpful diagnostically.

\section{Conflict of Interest}

None.

\section{References}

1 Savolainen VT, Liesto K, Männikkö A, Penttilä A, Karhunen PJ. Alcohol consumption and alcoholic liver disease: evidence of a threshold level of effects of ethanol. Alcohol Clin Exp Res 1993;17 (05):1112-1117

2 Crabb DW. Pathogenesis of alcoholic liver disease: newer mechanisms of injury. Keio J Med 1999;48(04):184-188

3 Mann RE, Smart RG, Govoni R. The epidemiology of alcoholic liver disease. Alcohol Res Health 2003;27(03):209-219

4 MacSween RN, Burt AD. Histologic spectrum of alcoholic liver disease. Semin Liver Dis 1986;6(03):221-232

5 Lefkowitch JH. Morphology of alcoholic liver disease. Clin Liver Dis 2005;9(01):37-53

6 Mandayam S, Jamal MM, Morgan TR. Epidemiology of alcoholic liver disease. Semin Liver Dis 2004;24(03):217-232

7 Bellentani S, Saccoccio G, Costa Get al.The Dionysos Study Group. Drinking habits as cofactors of risk for alcohol induced liver damage. Gut 1997;41(06):845-850

8 Vengeliene V, Bilbao A, Molander A, Spanagel R. Neuropharmacology of alcohol addiction. Br J Pharmacol 2008;154(02): 299-315

9 Thapa BR, Walia A. Liver function tests and their interpretation. Indian J Pediatr 2007;74(07):663-671

10 Cuschieri A, Baker PR. Gamma-glutamyl-transpeptidase in hepato-biliary disease-value as an enzymatic liver function test. $\mathrm{Br} \mathrm{J}$ Exp Pathol 1974;55(02):110-115

11 Mauro P, Renze B, Wouter WIn: Carl AB, Edward R, David EB, eds. Tietz Textbook of Clinical Chemistry and Molecular Diagnostics. 4th ed. Philadelphia, PA: Elsevier2006:604-616

12 Nagoshi S. Osteopontin: versatile modulator of liver diseases. Hepatol Res 2014;44(01):22-30

13 Wen Y, Jeong S, Xia Q, Kong X. Role of osteopontin in liver diseases. Int J Biol Sci 2016;12(09):1121-1128
14 Oldberg A, Franzén A, Heinegård D. Cloning and sequence analysis of rat bone sialoprotein (osteopontin) cDNA reveals an Arg-GlyAsp cell-binding sequence. Proc Natl Acad Sci U S A 1986;83(23): 8819-8823

15 Hu DD, Lin EC, Kovach NL, Hoyer JR, Smith JW. A biochemical characterization of the binding of osteopontin to integrins alpha $\mathrm{v}$ beta 1 and alpha v beta 5. J Biol Chem 1995;270(44):26232-26238

16 Denda S, Reichardt LF, Müller U. Identification of osteopontin as a novel ligand for the integrin alpha 8 beta 1 and potential roles for this integrin-ligand interaction in kidney morphogenesis. Mol Biol Cell 1998;9(06):1425-1435

17 Diana Nicoll CAppendix: therapeutic drug monitoring and laboratory reference ranges. In: Stephen JM, Maxine AP, eds. Current medical diagnosis and treatment. 46th ed. New York, NY: McGraw Hill2007:1767-1775

18 Senger DR, Wirth DF, Hynes RO. Transformed mammalian cells secrete specific proteins and phosphoproteins. Cell 1979;16(04): 885-893

19 Konttinen A, Härtel G, Louhija A. Multiple serum enzyme analyses in chronic alcoholics. Acta Med Scand 1970;188(04):257-264

20 Matloff DS, Selinger MJ, Kaplan MM. Hepatic transaminase activity in alcoholic liver disease. Gastroe-nterology 1980;78(06): 1389-1392

21 Moussavian SN, Becker RC, Piepmeyer JL, Mezey E, Bozian RC. Serum gamma-glutamyl transpeptidase and chronic alcoholism. Dig Dis Sci 1985;30(03):211-214

22 Das SK, Vasudevan DM. Biochemical diagnosis of alcoholism. Indian J Clin Biochem 2005;20(01):35-42

23 Maithreyi R, Janani AV, Krishna R, Shweta A, Edwin RR, Mohan SK. Erythrocyte lipid peroxidation and antioxidants in chronic alcoholics with alcoholic liver disease. Asian J Pharm Clin Res 2010; 3:183-185

24 Mirunalini S, Arulmozhi V, Arulmozhi T. Curative effect of garlic on alcoholic liver diseased patients. Jordan J Biol Sci 2010;3(04): $147-152$

25 Jang ES, Jeong SH, Hwang SHet al.Effects of coffee, smoking, and alcohol on liver function tests: a comprehensive cross-sectional study. BMC Gastroenterol 2012;12(01):145

26 Al-Jumaily EF. The effect of chronic liver diseases on some biochemical parameters in patients serum. Curr Res J Biol Sci 2012;4(05):638-642

27 Hyder MA, Hasan M, Mohieldein AH. Comparative levels of ALT, AST, ALP and GGT in liver associated diseases. Eur J Exp Biol 2013; 3(02):280-284

28 Gayathri B, Vasantha M. Comparative levels of liver enzymes in patients with various liver disorders. Int J Pharma Bio Sci 2015;6 (04):1099-1102

29 Brandl K, Hartmann P, Jih LJet al.Dysregulation of serum bile acids and FGF19 in alcoholic hepatitis. J Hepatol 2018;69(02):396-405

30 Hourigan KJ, Bowling FG. Alcoholic liver disease: a clinical series in an Australian private practice. J Gastroenterol Hepatol 2001;16 (10): $1138-1143$

31 Seth D, Duly A, Kuo PC, McCaughan GW, Haber PS. Osteopontin is an important mediator of alcoholic liver disease via hepatic stellate cell activation. World J Gastroenterol 2014;20(36):13088-13104

32 Teschke R, Neuefeind M, Nishimura M, Strohmeyer G. Hepatic gamma-glutamyltransferase activity in alcoholic fatty liver: comparison with other liver enzymes in man and rats. Gut 1983;24 (07):625-630

33 Benerji GV, Babu FM, Kumari RD, Saha A. Comparative study of ALT, AST, GGT \& uric acid levels in liver diseases. IOSR-JDMS 2013; 7(05):72-75

34 Agarwal S, Fulgoni VL, Lieberman HR. Assessing alcohol intake \& its dose dependent effects on liver enzymes by $24-\mathrm{h}$ recall and questionnaire using NHANES 2001-2010 data.. Nutrition Journal 2016:15-62 
108 The Role of GGT and OPN in Alcoholic Liver Disease Suri et al.

35 Arai M, Yokosuka O, Kanda Tet al.Serum osteopontin levels in patients with acute liver dysfunction. Scand J Gastroenterol 2006; 41(01):102-110

36 Zhao L, Li T, Wang Yet al.Elevated plasma osteopontin level is predictive of cirrhosis in patients with hepatitis B infection. Int J Clin Pract 2008;62(07):1056-1062

37 Patouraux S, Bonnafous S, Voican CSet al.The osteopontin level in liver, adipose tissue and serum is correlated with fibrosis in patients with alcoholic liver disease. PLoS One 2012;7(04):e35612
38 Fouad SA, Mohamed NA, Fawzy MW, Moustafa DA. Plasma osteopontin level in chronic liver disease and hepatocellular carcinoma. Hepat Mon 2015;15(09):e30753

39 Gogoi JB, Tyagi PK, Singh AK, Gairola K. Study of serum gamma glutamyltransferase as a diagnostic marker in alcoholic hepatitis. J Pharm 2012;2(04):69-71

40 Srungaram P, Rule JA, Yuan HJet al.Acute Liver Failure Study Group. Plasma osteopontin in acute liver failure. Cytokine 2015;73(02):270-276 